\title{
SEDIMENT AND SLUDGE DEWATERING AND TREATMENT: REAL EXAMPLES AND CASE STUDIES
}

HELENA NORD

RGS 90 SVERIGE $A B$,

Sweden

\begin{abstract}
Remediation of contaminated sediments is becoming more and more common in Sweden, and often the remediated sediments are accompanied by large amounts of water when remediation is done by suction dredging or excavation dredging. RGS 90 have developed techniques to dewater the remediated sediments to minimize the cost of treatment as well as the environmental impact (e.g. less transports are needed if the sediments are being dewatered on site). In the stream Viskan outside Borås in western Sweden, RGS 90 performed a suction dredging where the sediments were dewatered and stabilized. Also, in a pond near Kristinehamn in mid-Sweden, RGS 90 performed an excavation dredging where the sediments were dewatered on a tilting plane.
\end{abstract}

\section{KEYWORDS}

Redmediation; Sediment; Dredging; Dewatering.

\section{INTRODUCTION}

During centuries, industrial sites have been located near streams, lakes and the coasts of Sweden. The water provided energy as well as ways as transport and disposal sites for the industries of e.g. sawmills and technical industries where the waste water historically has been discharged with little or no treatment. As a result, the sediments have been polluted with various contaminants such as oils, metals and dioxins.

Nowadays, remediation of the sediments has been more and more common in Sweden. However, a large cost of the remediation is connected to the treatment of the sediments that commonly are very wet and often with a dry weight of less than $10 \%$. During suction dredging, the dry weight can be even lower, with only a few percent.

During dredging projects, RGS 90 are using different techniques on site to stabilize and dewater dredged sediments in order to reduce the need of transportation and the costs of treating sediments that has not been dewatered. In this presentation, two case studies will be presented.

https://doi.org/10.15626/Eco-Tech.2014.001 


\section{VISKAN, BORÅS}

In the stream Viskan, located near Borås in western Sweden, RGS 90 have performed remediation of polluted sediments. The city of Borås has a long industrial history with a focus on textile production, which has caused contamination of the sediments in Viskan, mainly with metals. Therefore, when the Swedish Transport Administration planned to build a new bridge over Viskan, the sediments needed to be remediated before the removal of the old bridge could begin.

The sediments were located in five different areas on both sides of Viskan, with contaminated, loose sediments with a dry weight content of about $23 \%$ over layering a hard bottom. The contaminations consisted of metals, PAHs and dioxin. Due to the steepness of the bank down to the river from the road with no place for an excavator in combination with the water depth, the dredging was performed as a suction dredging. The road was closed on one side and the dredging vehicles were placed on the road adjacent to the bank. A team of three divers then performed the suction dredging.

The dredged sediments were pumped into tank vehicles that transported the sediments to RGS 90:s facility in Borås. At the facility, RGS 90 had constructed a pond to which the sediments were pumped from the vehicles (the largest particles remained in the vehicles and were disposed separately). In the pond, the largest particles were allowed to sediment before they were pumped to large containers were the water was flocculated to remove the remaining particles. The treated water was then released into the sewage treatment plant of the facility.

The particles that settled in the pond and in the containers where then treated with lime ashes (a rest product from paper production) to stabilize the sediments. As a result of this treatment the sediment, instead of very wet and loose, became pileable and possible to handle like soil. Due to the contaminants in the sediments, they were then placed in a landfill.

In total, about $280 \mathrm{~m}^{3}$ of water and 130 tons of sediment were treated with this dewatering process. The dewatering reduced the costs with about $30 \%$, compared with transporting and treating the sediments without dewatering.

\section{KRISTINEHAMN}

Outside Kristinehamn in mid-Sweden, there have been oil depot sites. At the old oil harbor, a pond has been the last cleaning step of the water from the depot site. The pond is located adjacent to the largest lake in Sweden, Vänern. The sediment of the pond was heavily contaminated with hydrocarbons due to the oil activities in the area and contained a dry weight of about $35 \%$.

The client stipulated that the sediments needed to be dewatered before transportation to a waste facility. However, the suggestion was to make the dredging as a suction dredging. Since the pond was quite small, the dredging method could be changed to dredging with a longreach excavator, which enables the sediments to have higher dry weight content than if they were to be dredged with suctioning. Also, due to the small site it was necessary to use a dredging technique that produced a low amount of sediments that needed to be dewatered as well as a dewatering technique that did not need a large area. 
Since the wall towards Vänern was found to be leaking, a pump was installed in the pond to prevent contaminants that were swirling up due to the dredging to migrate through the wall and into Vänern. The water that was being pumped was lead through an oil separator as well as a filter with active carbon to ensure that the effluent water fulfilled the demands to be released back into Vänern.

To dewater the dredged sediments, a tilting plane was constructed at the site where the sediments were placed. The water from the sediments were then lead through the oil separator and the active carbon filter before it was released to Vänern. The dewatering process took about two months before the sediments could be transported away.

About 150 tons of sediments were dewatered in the dewatering process.

\section{CONCLUSIONS}

There are several different methods to dewater wet sediments on site or near site to reduce the costs of transport and treatment that otherwise would occur if the sediments were not dewatered. These alternatives are environmentally and economically favorable in comparison to transporting the sediments to a waste facility without previous treatment. 